\title{
Neural circuits can bridge systems and cognitive neuroscience
}

\author{
Linda Wilbrecht ${ }^{\text {* }}$ and Daphna Shohamy ${ }^{2 *}$ \\ ' Department of Neurology, Ernest Gallo Clinic and Research Center, University of California, San Francisco, Emeryville, CA, USA \\ 2 Department of Psychology, Columbia University, New York, NY, USA \\ Correspondence: */wilbrecht@gallo.ucsf.edu; **shohamy@psych.columbia.edu
}

There has been an emerging focus in neuroscience research on circuit-level interaction between multiple brain regions and behavior. This broad circuit-level approach creates a unique opportunity for convergence and collaboration between studies of humans and animal models of cognition.

Measurement of broad-scale brain networks may be particularly important for understanding changes that occur in brain organization and function during development. Recent studies in humans have gained much leverage from trying to understand circuit-level interactions among brain regions over the course of development. Such studies use connectivity analyses of functional magnetic resonance imaging both during cognitive activity and during rest (fcMRI), and diffusion tensor imaging (DTI) to measure (respectively) the functional and structural connectivity between discrete brain regions (e.g. Rissman et al., 2004; Snook et al., 2005; Mori and Zhang, 2006; Fox and Raichle, 2007). Studies using these approaches have revealed that, over the course of development, functional connectivity increases between distant brain regions (in the rostro-caudal axis) while it decreases between local regions of the frontal, parietal, and cingulate cortex (Fair et al., 2008). Developmental trajectories may be altered in diseased brains (e.g., Church et al., 2009), and functional and structural differences in connectivity may reflect individual differences in cognitive abilities (e.g., Niogi and McCandliss, 2006; Seeley et al., 2007; also see reviews this issue).

These findings emphasize the importance of understanding the development of associative neural circuits. Going forward, a key challenge will be to gain an understanding of what these circuits do during development at multiple levels of analysis, from cellular mechanism to cognitive function. Currently, the cellular and synaptic basis of changes in functional connectivity and DTI imaging remain unclear. Are these changes due to myelination, novel growth, elaboration or pruning of new connections? What happens when development is altered or connections are silenced?

Understanding the mechanistic basis of connectivity changes in humans, and how these changes relate to changes in behavior, is challenging and may benefit greatly from animal models. We propose that an emerging focus on broad-scale neural circuits provides a unique opportunity for collaborative studies that bridge research in mice and humans. New research methods and technology targeting neural circuits in both human and mouse neuroscience labs have great potential for enhancing overlap and collaboration between these two scientific cultures.

Furthermore, many of the cognitive paradigms in humans draw from, or have parallels in, the animal conditioning literature, such as reward prediction, reversal learning, relational memory, rule extraction, and set shifting. This overlap in behavioral paradigms and cognitive domains suggests the promise of integrating a circuit-level understanding of cognitive development across species. To facilitate such collaborations, there is a need for researchers to communicate across technical and cultural boundaries. Communication and education in the research possibilities available to each subfield will also facilitate the opportunity for researchers on both sides to make explicit predictions that can be tested in the most appropriate species, advancing research progress on common questions.

\section{WHAT MOUSE MODELS CAN OFFER DEVELOPMENTAL COGNITIVE NEUROSCIENCE}

Multimodal association areas are thought to support cognitive development and learning across mammalian species. Many of the same key cognitive regions of the brain (e.g. parietal and frontal cortex, basal ganglia, amygdala, and the hippocampus) can be found in both humans and mice and these broadly defined regions are connected in comparable circuits. For example, mice have cortical-basal ganglia loops and have parietal-frontal cortex and amygdala-frontal cortex connections. Elaboration and specialization of associative regions has likely occurred with evolution and growth in brain size, but the common genetic and anatomical architecture of the mammalian brain suggests similar rules may govern the development of basic associative brain circuits in mice and men alike.

Mice are particularly advantageous for study because of their relatively short development (puberty begins about 30 days of age, with adulthood at about 60 days), and their long history as a genetically tractable species, where increasingly specific identified populations of neurons can be genetically altered. Studies of the connectivity between association areas can be performed in mice with greater resolution to answer questions about the mechanisms regulating developmental circuit changes.

Thus, common circuit architecture in mice and humans offers the opportunity to perform controlled environmental, genetic, and behavioral experiments during development and adulthood. Such studies have enormous value, despite the obvious gaps in cognitive abilities between the species.

\section{TECHNOLOGIES FOR STUDYING CIRCUITS IN MICE WITH HIGH RESOLUTION}

New technologies have recently enhanced the study of neural circuits in mice, with important implications for understanding brain circuits underlying human cognitive development:

\section{IMAGING PLASTICITY AND ACTIVITY WITH CELLULAR AND SYNAPTIC RESOLUTION: 2PLSM}

Two photon laser scanning microscopy (2PLSM) through a thin skull or cranial window allows time- lapse imaging of dendrites, spines and axonal and boutons in developing and adult mice (Holtmaat et al., 2009). Chronic preparations allow longitudinal study of developmental or 
experience-dependent process or the time scales of hours to several months. Imaging studies to date have revealed spine and bouton loss and gain, and reorganization of axonal arbors in the living brain. Similar imaging techniques can also be used to monitor cellular activity using calcium sensitive indicators (Stosiek et al., 2003; Dombeck et al., 2007). These techniques can become particularly powerful as identified cell types or cells with known afferents or efferents can be identified via fluorescent genetic labeling strategies.

\section{MAPPING LONG-RANGE CONNECTIONS BETWEEN SPECIFIC NEURON TYPES: CRACM}

Light can also be used to isolate and measure the function of long-range connections between identified neurons. Channel Rhodopsin Assisted Circuit Mapping (CRACM) (Petreanu et al., 2007) uses ion channels "borrowed" from light sensitive bacteria to stimulate activity in channel expressing neurons (Boyden et al., 2005). Genetic and viral tricks allow light sensitive ion channels to be delivered to the membranes of specific cells or regions of interest, loading even long-range axons that traverse large portions of the brain (Petreanu et al., 2007). Expression of the channel in cells of interest enables isolated stimulation of cells or even severed axon terminals of interest (without stimulation of neighboring cells) by easily delivered remote flashes of blue light. Ex vivo slice patch clamp recording of cells in a specific location, or cells labeled with genetic tools, enables measurement of long-range afferent synapses made between specific cell types.

\section{MAPPING LOCAL CIRCUIT CONNECTIVITY BETWEEN SPECIFIC NEURON TYPES: LSPS}

Local circuit connectivity can also be measured using light. Laser scanning photostimulation (LSPS) uses light to uncage neurotransmitters in a defined region (Katz and Dalva, 1994). Light based uncaging produces focused concentration of transmitter, which can be used to cause action potentials at soma near the uncaging beam focus. With patch clamp recording of a single neuron and controlled scanning of an uncaging beam to distributed points across a brain slice it is possible to map local connections between a patched cell and its neighbors.

2PLSM, CRACM, and LSPS techniques have first been applied to sensory cortices in mice and are now beginning to be applied to motor areas (Zuo et al., 2005; Yu et al., 2008; Xu et al., 2009). An important next step is to apply these technologies to multimodal association areas and the development of circuits that connect them. Studies of association area connectivity in mice should be of great interest to developmental cognitive neuroscience. For example, changes in the "default state network" that occur with development or disease could be modeled by looking at changes in parallel areas in mice.

Some questions that can be answered with mouse experiments:

- Which synapses are generally pruned with development? Which are gained?

- How are the connections between brain regions (long range and short range) altered by the maturation of inhibition and the connectivity of local cortical circuits?

- Which cell types within these regions demonstrate the most radical developmental changes? What modulates these changes? Which genes are unique to these cell types?

- How do genetic differences and/or experience alter developmental circuit changes in a controlled environment?

- How do cellular level changes in circuits correlate with changes in behavior?

\section{HOW CAN CONVERGING STUDIES OF CIRCUIT DEVELOPMENT ALSO ADVANCE OUR UNDERSTANDING OF COGNITIVE DEVELOPMENT?}

To maximize the knowledge gained from comparative study of mice and humans it is important to take into account species differences in evolution and behavior and select the most auspicious cognitive comparisons. Many would agree that emotional and motivational behaviors supported by limbic, basal ganglia, and midbrain structures are readily comparable between species. Cortex-based cognition in mice and humans may differ both qualitatively and quantitatively, yet the sophistication of mouse cognition should not be underestimated. Mice are capable of rapid associative learning and reversal of learned associations (within a single training session) on tasks designed to approximate tests for humans with frontal lobe damage (Bissonette et al., 2008). The role of learning, memory and reward in decision making has also been found to be highly nuanced in studies of rodents and may be supported by distinct subcircuits that are parallel to those found in humans (E.g. Dusek and Eichenbaum, 1997; Shohamy and Wagner, 2008; see Eichenbaum and Cohen, 2001; Yin and Knowlton, 2006; Schoenbaum et al., 2009 for reviews).

When making cross species comparisons it should be noted mice tend to learn cognitive tasks using olfactory cues more efficiently, but they can also discriminate tactile, aural, and visual cues. The complexity of human social systems and the lack of pheromonerelated circuits in humans may make comparison of social cognition between species more difficult. Although behavior may not align perfectly in mice and men, with careful selection of cognitive measures with regard to ethological caveats we can enhance our understanding of the basic function of relays between associative regions.

Studies of mouse association circuits can also provide a bridge between genetics and behavior. Studies that attempt to link human genetic variation to disease have not been as clear as once hoped (Goldstein, 2009), and this is especially true for psychiatric disease. A search for common biological pathways and cellular and circuit endophenotypes that link rare genetic variants may be more successful (Hirschhorn, 2009). The effect of human genetic variants on neural circuit development and plasticity may be readily tested in mice at both the circuit and behavioral level. Furthermore, imaging in awake mice and repeat longitudinal imaging allows for greater possibility and power in assessing correlations between developmental cognitive changes, cellular level circuit measures, and genetic differences.

Studies of whole brains or multiple brain regions and correlations between them can be performed most efficiently in human studies. These studies, along with genetic data, can then be used to pinpoint circuits and cells for further study with higher resolution in mice.

Studies of the brain are revealing that specialized knowledge is most powerful when shared across networks. Ideally, neuroscientists studying humans and mice can similarly work and move forward together.

\section{ACKNOWLEDGMENTS}

The authors thank Itamar Kahn for discussion and comments. 


\section{REFERENCES}

Bissonette, G. B., Martins, G. J., Franz, T. M., Harper, E. S., Schoenbaum, G., and Powell, E. M. (2008). Double dissociation of the effects of medial and orbital prefrontal cortical lesions on attentional and affective shifts in mice. J. Neurosci. 28 , $11124-11130$

Boyden, E. S., Zhang, F., Bamberg, E., Nagel, G., and Deisseroth, K. (2005). Millisecond-timescale, genetically targeted optical control of neural activity. Nat. Neurosci. 8, 1263-1268.

Church, J. A., Fair, D. A., Dosenbach, N. U., Cohen, A. L., Miezin, F. M., Petersen, S. E., and Schlaggar, B. L. (2009). Control networks in paediatric Tourette syndrome show immature and anomalous patterns of functional connectivity. Brain 132(Pt 1), 225-238.

Dombeck, D. A., Khabbaz, A. N., Collman, F., Adelman, T. L., and Tank, D. W. (2007). Imaging large-scale neural activity with cellular resolution in awake, mobile mice. Neuron 56, 43-57.

Dusek, J.A., and Eichenbaum, H. (1997). The hippocampus and memory for orderly stimulus relations. Proc. Natl. Acad. Sci. U.S.A. 94, 7109-7114.

Eichenbaum, H. E., and Cohen, N. J. (2001). From Conditioning to Conscious Recollection: Memory Systems of the Brain. New York, Oxford University Press.

Fair, D. A., Cohen, A. L., Dosenbach, N. U., Church, J. A., Miezin, F. M., Barch, D. M., Raichle, M. E., Petersen, S. E., and Schlaggar, B. L. (2008). The maturing architecture of the brain's default network. Proc. Natl. Acad. Sci. U.S.A. 105, 4028-4032.

Fox, M. D., and Raichle, M. E. (2007). Spontaneous fluctuations in brain activity observed with functional magnetic resonance imaging. Nat. Rev. Neurosci. 8, 700-711.

Goldstein, D. B. (2009). Common genetic variation and human traits. N. Engl. J. Med. 360, 1696-1698.
Hirschhorn, J. (2009). Genomewide association studiesilluminating biological pathways. N. Engl. J. Med. 360 1699-1701.

Holtmaat, A., Bonhoeffer, T., Chow, D. K., Chuckowree, J., De Paola, V., Hofer, S. B., Hübener, M., Keck, T. Knott, G., Lee, W. C. , Mostany, R., Mrsic-Flogel, T. D. , Nedivi, E., Portera-Cailliau, C., Svoboda, K., Trachtenberg, J. T., and Wilbrecht, L. (2009). Longterm, high-resolution imaging in the mouse neocortex through a chronic cranial window. Nat Protoc. $4,1128-1144$

Katz, L. C., and Dalva, M. B. (1994). Scanning laser photostimulation: a new approach for analyzing brain circuits. J. Neurosci. Methods. 54, 205-218.

Mori, S., and Zhang, J. (2006). Principles of diffusion tensor imaging and its applications to basic neuroscience research. Neuron 51, 527-539.

Niogi, S. N., and McCandliss, B. D. (2006). Left lateralized white matter microstructure accounts for individual differences in reading ability and disability. Neuropsychologia 44, 2178-2188.

Petreanu, L., Huber, D., Sobczyk, A., and Svoboda, K. (2007). Channelrhodopsin-2-assisted circuit mapping of long-range callosal projections. Nat. Neurosci. $10,663-668$.

Rissman, J., Gazzaley, A., and D'Esposito, M. (2004). Measuring functional connectivity during distinct stages of a cognitive task. Neuroimage 23 , 752-763.

Schoenbaum, G., Roesch, M. R., Stalnaker, T. A., and Takahashi, Y. K. (2009). A new perspective on the role of the orbitofrontal cortex in adaptive behaviour. Nat. Rev. Neurosci. 10, 885-892.

Seeley, W. W., Menon, V., Schatzberg, A. F., Keller, J., Glover, G. H., Kenna, H., Reiss, A. L., and Greicius, M. D. (2007). Dissociable intrinsic connectivity networks for salience processing and executive control. J. Neurosci. 27, 2349-2356.
Shohamy, D. and Wagner, A. D. (2008). Integrating memories in the human brain: hippocampal-midbrain encoding of overlapping events. Neuron 60 , 378-389.

Snook, L., Paulson, L.A., Roy, D., Phillips, L., and Beaulieu, C. (2005). Diffusion tensor imaging of neurodevelopment in children and young adults. Neuroimage. 26, 1164-1173.

Stosiek, C., Garaschuk, O., Holthoff, K., and Konnerth, A. (2003). In vivo two-photon calcium imaging of neuronal networks. Proc. Natl. Acad. Sci. U.S.A. 100, 7319-7324.

Xu, T., Yu, X., Perlik, A.J., Tobin, W.F.,Zweig, J.A., Tennant, K., Jones, T., and Zuo, Y. (2009). Rapid formation and selective stabilization of synapses for enduring motor memories. Nature 462, 915-919.

Yin, H. H., and Knowlton, B. J. (2006). The role of the basal ganglia in habit formation. Nat. Rev. Neurosci. 7, 464-476.

Yu, J., Anderson, C. T., Kiritani, T., Sheets, P. L., Wokosin, D. L., Wood, L., and Shepherd, G. M. (2008). Localcircuit phenotypes of layer 5 neurons in motor-frontal cortex of YFP-H mice. Front. Neural Circuits. 2, 6. doi: 10.3389/neuro.04.006.2008.

Zuo, Y., Lin, A., Chang, P., and Gan, W. B. (2005). Development of long-term dendritic spine stability in diverse regions of cerebral cortex. Neuron. 46 , 181-189.

Received: 03 September 2009; accepted: 04 January 2010; published: 20 January 2010.

Citation: Front. Hum. Neurosci. (2010) 3:81. doi: 10.3389/neuro.09.081.2009

Copyright $\odot 2010$ Wilbrecht and Shohamy. This is an openaccess publication subject to an exclusive license agreement between the authors and the Frontiers Research Foundation which permits unrestricted use, distribution, and reproduction in any medium, provided the original authors and source are credited. 